\title{
Fast Blue RR-Siloxane Derivatized Materials Indicate Wound Infection Due to a Deep Blue Color Development
}

\author{
Doris Schiffer ${ }^{1, *}$, Gregor Tegl ${ }^{2}$, Robert Vielnascher ${ }^{2}$, Hansjoerg Weber ${ }^{3}$, Rainer Schoeftner ${ }^{4}$, \\ Herfried Wiesbauer ${ }^{4}$, Eva Sigl ${ }^{5}$, Andrea Heinzle ${ }^{1}$ and Georg M. Guebitz ${ }^{1,2}$ \\ Received: 29 June 2015 ; Accepted: 21 September 2015 ; Published: 25 September 2015 \\ Academic Editor: Jun-ichi Anzai \\ 1 ACIB-Austrian Centre of Industrial Biotechnology, Konrad-Lorenz Strasse 203630 Tuln, Graz 8010, \\ Austria; andrea.heinzle@qualizyme.com (A.H.); guebitz@boku.ac.at (G.M.G.) \\ 2 Department of Environmental Biotechnology, University of Natural Resources and Life Sciences Vienna, \\ Konrad Lorenz Strasse 20, 3430 Tulln an der Donau, Vienna 1180, Austria; gregor.tegl@boku.ac.at (G.T.); \\ robert.vielnascher@boku.ac.at (R.V.) \\ 3 Department of Organic Chemistry, Technical University Graz, Stremayrgasse 16, 8010 Graz, Austria; \\ hansjoerg.weber@tugraz.at \\ 4 Functional Surfaces \& Nanostructures, PROFACTOR GmbH, Im Stadtgut A2, Steyr-Gleink 4407, Austria; \\ rainer.schoeftner@profactor.at (R.S.); herfried.wiesbauer@profactor.at (H.W.) \\ 5 Qualizyme GmbH, Neue Stiftingtalstrasse 2, Graz 8010, Austria; eva.sigl@qualizyme.com \\ * Correspondence: doris.schiffer@acib.at; Tel.: +43-2272-66280-502; Fax: +43-2272-66280-503
}

\begin{abstract}
There is a strong need for simple and fast methods for wound infection determination. Myeloperoxidase, an immune system-derived enzyme was found to be a suitable biomarker for wound infection. Hence, alkoxysilane-derivatized Fast Blue RR was immobilized via simple hydrolytic polymerization. The resulting enzyme-responsive siloxane layers were incubated with myeloperoxidase, wound fluid or hemoglobin. The reaction was monitored via HPLC measurements and the color development quantified spectrophotometrically. Myeloperoxidase was indeed able to oxidize immobilized Fast Blue RR leading to a blue colored product. No conversion was detected in non-infected wound fluids. The visible color changes of these novel materials towards blue enable an easy distinction between infected and non-infected wound fluids.
\end{abstract}

Keywords: immobilization; Fast Blue RR; alkoxysilane derivatized Fast Blue RR; myeloperoxidase; infection detection

\section{Introduction}

Standard procedures for wound infection detection are time consuming (microbiology) or show limited reliability due to the judgement of the classical clinical signs, redness (rubor), heat (calor), swelling (tumor), and pain (dolor) or due to the detection of signals specific to secondary wounds [1-3]. Hence, alternative methods based on the assessment of biomarkers like metabolites, enzymes or microbes have been suggested [4]. New point-of-care devices should facilitate the diagnosis and treatment of chronic wounds [5]. Various enzymes of the immune system accumulate in the wound fluid during an infection, having a potential as biomarkers for infection detection [6]. Myeloperoxidase (MPO), an enzyme derived from the neutrophils is one of the first enzymes present on site of injury. During the oxidative burst, MPO uses the generated hydrogen peroxide to build highly reactive $\mathrm{HOCl}$, and contributes to the destruction of invading bacteria. Myeloperoxidase shows about ten times higher activities in infected wounds compared to non-infected wounds [7]. The potential of this enzyme was furthermore confirmed in a correlation study with silver standard 
wound diagnostics [7]. New substrates for myeloperoxidase were tested including Fast Blue RR (4-benzoylamino-2,5-dimethoxybenzenediazonium chloride hemi (zinc chloride) salt) that show significant differences in color development and in the indication of infections in wounds [8].

Fast Blue RR salt is commonly used for the detection of esterase and alkaline phosphatase activities in histochemical and colorimetric analysis [9]. In these reactions, naphthyl derivatives are applied as substrates and the enzymatic release of naphthol is followed via a coupling reaction with a diazonium salt such as Fast Blue RR. These reactions are usually performed in basic media and the formations of colored derivatives take only a few minutes. Applications are found in assays for the determination of esterases as pro-drug target in prostate cancer, or to determine the content of alkylresorcinols (ARs) in ground and whole cereal grains [10,11].

Diagnostic devices in wound care should deliver fast results while being user friendly. Hence, simple handling of point-of-care devices is often achieved by immobilization of the diagnosing compound onto carrier materials. Obviously simple immobilization strategies are essential for large scale production of test strips. Alkoxysilane based substrates would allow the formation of functionalized siloxane layers on a large variety of material surfaces via simple hydrolytic polymerization. Such simple enzyme-responsive surfaces could facilitate wound infection diagnosis and treatment.

\section{Results and Discussion}

Recent studies confirmed the suitability of myeloperoxidase (MPO) for infection detection in wounds [8]. Significant differences in enzyme activity were observed comparing infected and non-infected wound fluids, using the well-known substrate guaiacol that can be spectrophotometrically detected. However, it is not possible to covalently immobilize guaiacol without rendering it inactive towards MPO mediated oxidation.. Hence, Fast Blue RR was covalently coupled to alkoxysilanes allowing the simple formation of enzyme-responsive siloxane layers on a variety of surfaces. Figure 1 shows the coupling reaction and the final product that was analyzed with NMR spectroscopy.

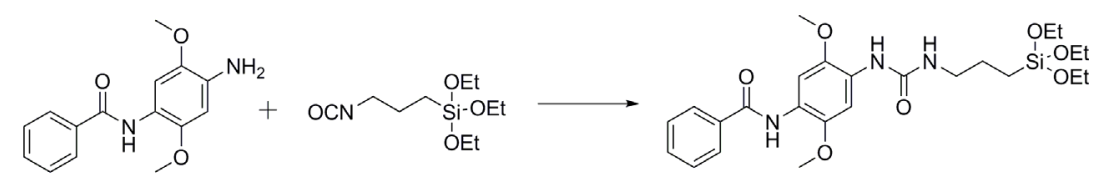

Figure 1. Derivatized Fast Blue RR:Fast blue RR was coupled to 3-(triethoxysilyl)propyl isocyanate. NMR measurements confirm the structure of the stable product.

Simple hydrolytic polymerization of this enzyme-responsive substrate enables the application in test strips for early-stage wound infection detection. Thereby it is essential to consider cross reactions with hemoglobin, likewise present in wound fluids. After immobilization of the substrate onto silica plates as model carrier, the reactivity was tested with pure enzyme (MPO), hemoglobin as well as with infected and non-infected wound fluids. A fast color change towards blue (10-30 $\mathrm{min}$ ) was recorded (Figure 2). The hemoglobin content of the wound fluid was determined prior to the incubation with the substrate and was found to be $0.007 \mathrm{mM}$. Figure 2 shows the blue color development of the enzyme-responsive siloxane layer upon incubation. A significant difference in the delta E values was observed with infected compared to non-infected wound fluids with a $p$ value of less than 0.001. The color development in Figure 2 shows the progression from 30 to $60 \mathrm{~min}$. An incubation interval of $30 \mathrm{~min}$ already provides a statistically significant discrimination between infected and non-infected wound fluids. Cross-reactions with hemoglobin occur, but the delta $\mathrm{E}$ values show $60 \%$ less color development in samples with a higher hemoglobin content compared to the infected wound fluid sample. Significant differences, independent of the time interval are indicated in Figure 2, representing $\mathrm{p}$ values of less than 0.001 . Infection detection in wounds still consititutes a challenging 
topic in medicine. New detection methods of elevated enzyme activity in wounds include ELISA based assays and colorimetric assays. A combination of both, like in the SIEFED technique (Specific Immuno Extraction Followed by Enzymatic Detection) could also play a role in MPO determination in the future [12]. It is moreover important to shorten the reaction times as well as the pre-handling procedures. Enzyme-triggered color changes on a surface in a short time period represent a suitable tool for a fast assumption of the wound status.

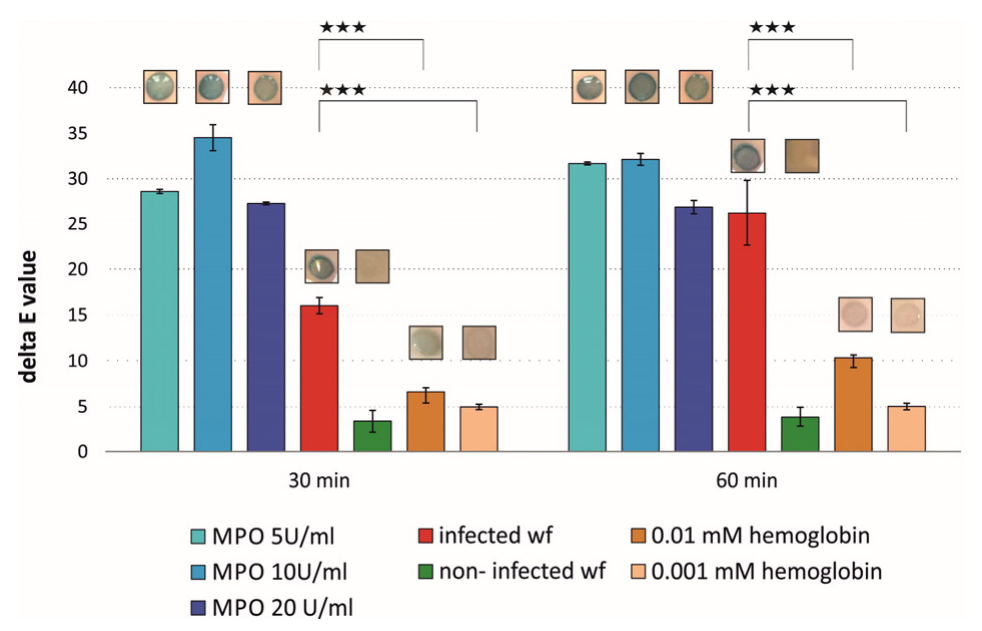

(a)

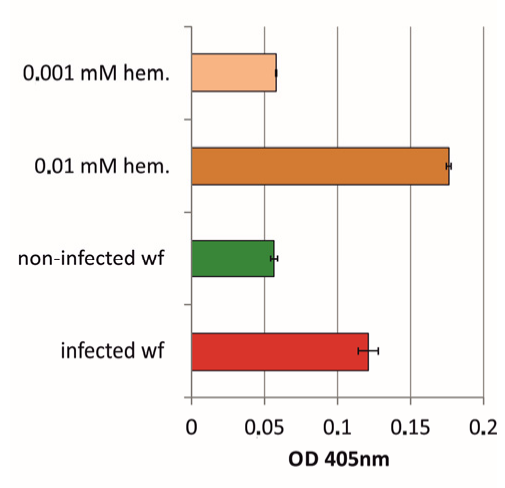

(b)

Figure 2. (a) Color formation of immobilized alkoxysilane-derivatized Fast Blue RR upon incubation with MPO and wound fluids: alkoxysilane-derivatized Fast Blue RR was polymerized and the resulting enzyme-responsive siloxane layer incubated with different enzyme activities of pure MPO, infected and non-infected wound fluids as well as different concentrations of hemoglobin over a time period of $30 \mathrm{~min}$ and $60 \mathrm{~min}$. The blue color formation upon conversion of the substrate was quantified with a ColorLite sph850 spectrophotometer and is given as in delta E values. Two-sample t-tests assuming equal variances were performed, $p$-values equal or less than 0.001 were considered as significant $(* * *)$. (b) The hemoglobin concentration of the infected and non-infected wound fluid was determined prior to the immobilization experiments.

\subsection{LC-ESI-TOF}

In order to investigate MPO oxidation of alkoxysilane-derivatized Fast Blue RR, LC-MS experiments were conducted. Two different $\mathrm{pH}$ values were investigated comparing the reaction kinetics at physiological conditions and at acidic $\mathrm{pH}$. Similar to other MPO substrates like guaiacol, LC-ESI-TOF indicated that oxidation of alkoxysilane-derivatized Fast Blue RR led to the formation of a variety of oligomers [13]. Hence, the reaction was monitored based on the consumption of alkoxysilane-derivatized Fast Blue RR. For both $\mathrm{pH}$ values a substantial decrease within $60 \mathrm{~min}$ was observed by LC and ESI-TOF (Figure 3). An immediate Fast Blue RR consumption of alkoxysilane-derivatized Fast Blue $\mathrm{RR}$ was observed at $\mathrm{pH} 4$, however, similar results at both $\mathrm{pH}$ values were obtained for the subsequent time measurements. It is supposed the alkoxysilane-derivatized Fast Blue RR is less stable under acidic conditions, which leads to a partial degradation of the substrate prior to enzymatic conversion. The LC data shows a fast consumption of the enzyme responsive material with full conversion observed already after $6 \mathrm{~h}$. 


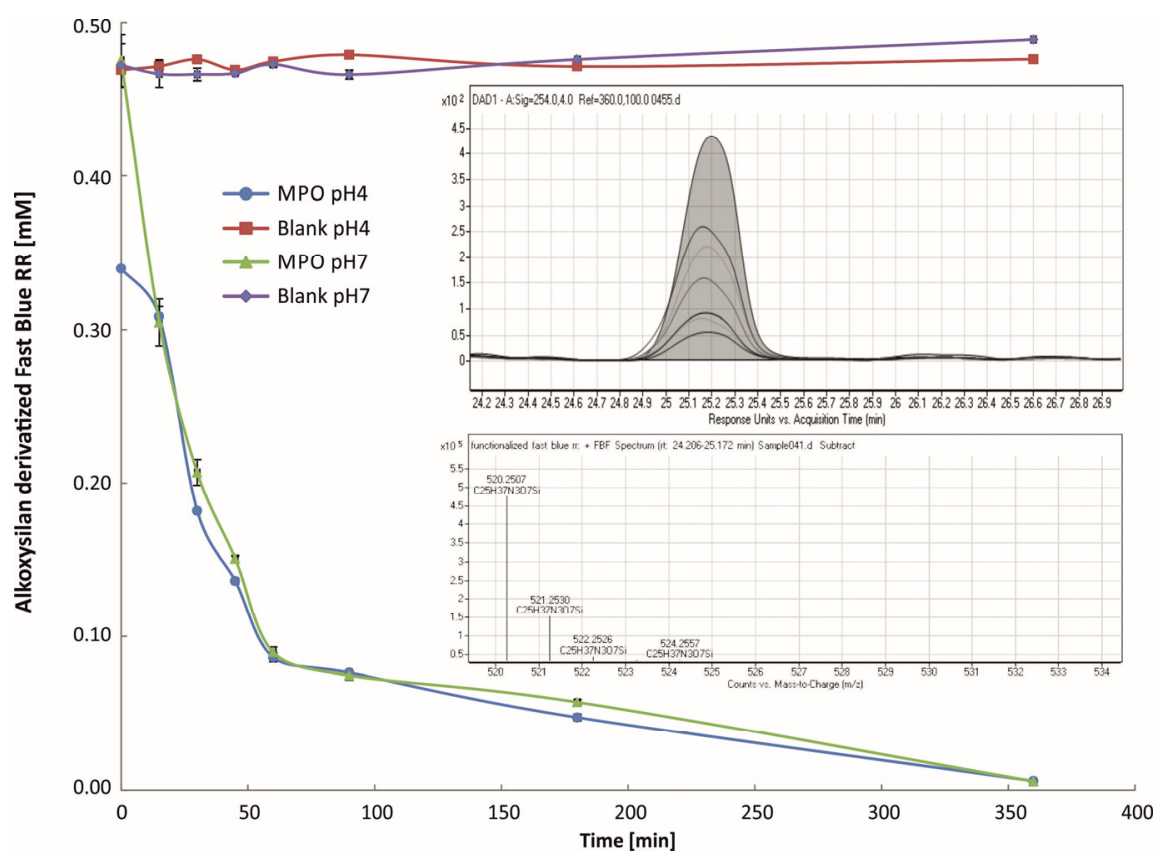

Figure 3. LC-MS TOF analysis of alkoxysilane-derivatized Fast Blue RR conversion by MPO: A substantial conversion of substrate could be observed already after several minutes at both $\mathrm{pH}$ values. After $6 \mathrm{~h}$ incubation time no substrate could be detected anymore by LC-ESI TOF. The graphs inside the figure depict the decrease of substrate illustrated as the function the substrate mass being 520.25.

Both the color reaction of the enzyme-responsive siloxane layer and LC-ESI TOF results reveal the suitability of derivatized Fast Blue RR being an effective system for a sensitive detection of elevated MPO activity after short time. The fast response within the first minutes of reaction time renders this detection system a promising candidate for the incorporation into point-of-care diagnostics. Additionally, the functional spacer facilitates the attachment on various surfaces.

\section{Experimental Section}

\subsection{Wound Fluid Collection and Microbiological Determination}

Before sample collection, wounds were cleaned with $0.9 \% \mathrm{NaCl}$ (Sigma Aldrich, St. Louis, MO, USA) to remove superficial bacteria. Wound fluid was taken with nylon swabs, of the most contaminated and/or deep site of the wound bed and/or wound edges. The samples were analyzed with MALDI TOF techniques, addressing the analyses of the occurring species, and Gram staining-dependent microscopy evaluations were performed to determine the bacterial load. After Gram staining, the slides were screened (magnification 1000 $\times$ ) and the bacterial count was reported. The semi-quantitative reporting system was subdivided from $+(<1)$ to $+++(>100)$ counts per ocular field. The microbiological test results were categorized as "infected", or "non-infected", by looking for the presence of potential pathogenic microorganisms (ppmos) relative to the general microbiological flora.

\subsection{Functionalization of Fast Blue RR}

Fast blue RR (N-(4-amino-2,5-dimethoxyphenyl) benzamide) was coupled to alkoxysilanes for immobilization. The coupling was performed according to Hasmann [8] and the molecular structure of the synthesized substrate was proven by $1 \mathrm{H}$ and $13 \mathrm{C}$ nuclear magnetic resonance (NMR). NMR spectra were measured on a Bruker Avance 3 (Bruker, Bremen, Germany) at $300 \mathrm{MHz}$ for protons 
and $75 \mathrm{MHz}$ for 13C. The derivatized Fast Blue RR was dissolved in DMSO-d6. Sixteen scans were accumulated for $1 \mathrm{H}$ and 2048 scans for $13 \mathrm{C}$.

\subsection{Immobilization of Derivatized Fast Blue RR}

As a model surface for hydrolytic polymerization of alkoxysilane-derivatized Fast Blue RR silica thin-layer chromatography (TLC) plates were used. $1 \mathrm{~cm} \times 1 \mathrm{~cm}$ squares were cut and overlaid with a $50 \mathrm{mM}$ solution of derivatized Fast Blue RR dissolved in $\mathrm{EtOH}$. The polymerization was performed for $24 \mathrm{~h}$ at $105^{\circ} \mathrm{C}$.

\subsection{Transformation of the Substrate}

The transformation of alkoxysilane-derivatized Fast Blue RR was carried out using pure myeloperoxidase (MPO, planta), infected and non-infected wound fluid (wf) of ulcer wounds and hemoglobin (Sigma, St. Louis, MO, USA). Wound fluids were collected as described in Schiffer et al. [6]. MPO was diluted in potassium phosphate buffer (100 mM; pH 7) to (end) concentrations of $20 \mathrm{U} / \mathrm{mL} ; 10 \mathrm{U} / \mathrm{mL} ; 5 \mathrm{U} / \mathrm{mL}$. The wound fluids were diluted in potassium phosphate buffer (100 mM; pH 7) or sodium acetate buffer (100 mM; pH 4), and hemoglobin was used in end concentrations of $0.01 \mathrm{mM}, 0.05 \mathrm{mM}$ and $0.001 \mathrm{mM}$. The wound fluids and the hemoglobin dilutions were additionally measured at $405 \mathrm{~nm}$ to compare the hemoglobin content of the wound fluid and the hemoglobin solutions.

Ten $\mu \mathrm{l}$ of the respective solutions were mixed with ten $\mu \mathrm{l}$ of $39.2 \mathrm{mM} \mathrm{H}_{2} \mathrm{O}_{2}$ solution and pipetted on the silica plates with the immobilized substrate. Solutions lacking $\mathrm{H}_{2} \mathrm{O}_{2}$ were used as blanks.

Additionally, the visual inspection of the silica plates after $30 \mathrm{~min}$ and $60 \mathrm{~min}$, the color changes on the surface of the silica plates were measured with a ColorLite sph850 spectrophotometer (ColorLite $\mathrm{GmbH}$, Katlenburg-Lindau, Germany). As a reference, a wetted silica plate with immobilized substrate, but without enzyme was used. Based on the delta E values, calculations and statistical analyses were performed. To compare the different experimental setups regarding the statistical significance, Two-sample t-tests assuming equal variances were performed. A p-value of less than 0.001 was considered as statistical significant.

\subsection{HPLC Sample Treatment}

The sample preparation of HPLC analysis was carried out as follows. The working solutions $(1 \mathrm{~mL})$ contained $20 \mathrm{mM}$ of the derivatized Fast Blue RR, $1.5 \mathrm{U} / \mathrm{mL} \mathrm{MPO}, 39.2 \mathrm{mM} \mathrm{H}_{2} \mathrm{O}_{2}, 50 \mathrm{mM}$ $\mathrm{NaCl}$ in $100 \mathrm{mM}$ potassium phosphate buffer ( $\mathrm{pH} 7)$ or sodium acetate buffer $(\mathrm{pH} 4)$. As negative controls, all samples were also prepared leaving out MPO. The samples were incubated for 0, 15, 30, 45, 60, 90, 180, and 360 minutes. After these time points, $1 \mathrm{~mL}$ absolute EtOH was added and the acidic samples were adjusted to a $\mathrm{pH}$ of 7. A Carrez clarification was performed. $20 \mu \mathrm{L}$ of $\mathrm{C} 1$ solution $\left(5.325 \mathrm{~g}\right.$ of $\mathrm{K}_{4}\left[\mathrm{Fe}(\mathrm{CN})_{6}\right]^{* 3} \mathrm{H}_{2} \mathrm{O}$, dissolved in water filled up to a volume of $50 \mathrm{~mL}$ ) was added to the samples and vortexed for 1 minute. Subsequently $20 \mu \mathrm{L}$ of $\mathrm{C} 2$ solution was added (14.400 $\mathrm{g}$ of $\mathrm{ZnSO}_{4}{ }^{*} 7 \mathrm{H}_{2} \mathrm{O}$, dissolved in water, filled up to a volume of $50 \mathrm{~mL}$ ) $5 \mathrm{~min}$ shaked and an centrifuged $(15,000 \mathrm{rpm})$ for $15 \mathrm{~min}$. Five hundred $\mu \mathrm{L}$ of the samples were again mixed with $500 \mu \mathrm{L}$ of EtOH absolute and purified using a $45 \mu \mathrm{m}$ filter. The samples were then distributed (250 $\mu \mathrm{L}$ each) in HPLC vials.

\subsection{HPLC Measurement}

\subsubsection{LC}

A LC 1260 pump (Agilent G1312B, Palo Alto, CA, USA) was operated using $20 \mathrm{mM}$ ammonia formiate in water and acetonitrile as mobile phase. A gradient was set from $0 \%$ to $100 \%$ acetonitrile within $35 \mathrm{~min}$ in a $45 \mathrm{~min}$ method. The Column Poroshell $120 \mathrm{EC}-\mathrm{C} 184.6 \mathrm{~mm} \times 50 \mathrm{~mm} 2.7 \mathrm{Micron}$ 
(Agilent, Palo Alto, CA, USA) was equilibrated at $40{ }^{\circ} \mathrm{C}$ in a 1290 Infinity 2 TCC (Agilent G7116B) with $80 \%$ water $20 \mathrm{mM}$ ammonia formiate and acetonitrile for $60 \mathrm{~min}$. The LC-MS grade water was purified by an ELGA PURELAB ultra (VWS). All other chemicals were supplied from Sigma Aldrich (St. Louis, MO, USA) in LC-MS grade.

\subsubsection{LC-ESI TOF}

The LC was coupled to a DAD (Agilent G4212B, Palo Alto, CA, USA) and a Dual ESI G6230B TOF (Agilent, Palo Alto, CA, USA). For the electrospray ionization (operating in positive ion mode), a nebulizer was used, the dry gas flow was set to $8 \mathrm{~L} / \mathrm{min}$ and a pressure of 40 psig at $250{ }^{\circ} \mathrm{C}$ was chosen. The fragmenter voltage was set to $200 \mathrm{~V}$, the skimmer at $65 \mathrm{~V}$, the octopole to a voltage of $750 \mathrm{~V}$ and the reference masses were $121.0509 \mathrm{~m} / \mathrm{z}$ and $922.0098 \mathrm{~m} / \mathrm{z}$. Ions from $50 \mathrm{~m} / \mathrm{z}$ to $3000 \mathrm{~m} / \mathrm{z}$ were acquired with the Agilent MassHunter Workstation (Version B06.01, Palo Alto, CA, USA). The DAD signal at $254 \mathrm{~nm}$ was also monitored by the Agilent MassHunter Workstation. A statistical calculation in accordance to German industrial standard 32645 for the detection limit, detectability limit, and limit of determination was performed. Significance was tested with p-values less than 0.05.

\section{Conclusions}

Fast Blue RR acts as a suitable marker for the detection of infection. Upon incubation with MPO or infected wound fluid, a blue color development was observed on polymerized alkoxysilane-derivatized Fast Blue RR layers. Cross reactions with hemoglobin occur but delta $E$ values as well as the visual inspection confirm a negligible color development compared to pure MPO solutions or infected wound fluids. LC-ESI TOF analyses further confirm the conversion of the substrate by $\mathrm{MPO}$ at different $\mathrm{pH}$ values. This derivatized substrate could facilitate the determination of infection in wounds.

Author Contributions: Doris Schiffer did the main experiments as well as the coordination of the measurements, she wrote main parts of the manuscript. Gregor Tegl planned the analytical experiments and was responsible for the analytical part of the manuscript. Robert Vielnascher realized the LC-ESI TOF experiments in the lab as well as the analyses and calculations. Hansjörg Weber did the NMR measurements as well as the analyses of the results. Rainer Schöftner and Herfried Wiesbauer functionalized the substrate Fast blue RR. Andrea Heinzle, Eva Sigl and Georg Gübitz participated in discussions, gave technical support and conceptual advice and reviewed the article.

Conflicts of Interest: The authors declare no conflict of interest.

\section{References}

1. Gardner, S.; Frantz, R.A.; Doebbeling, B.N. The validity of the clinical signs and symptoms used to identify localized chronic wound infection. Wound Repair Regen. 2001, 9, 178-186. [CrossRef] [PubMed]

2. Gardner, S.E.; Frantz, R.A.; Saltzman, C.L.; Hillis, S.L.; Park, H.; Scherubel, M. Diagnostic validity of three swab techniques for identifying chronic wound infection. Wound Repair Regen. 2006, 14, 548-557. [CrossRef] [PubMed]

3. Gardner, S.E.; HIillis, S.L.; Frantz, R.A. Clinical signs of infection in diabetic foot ulcers with high microbial load. Biol. Res. Nurs. 2010, 11, 119-128. [CrossRef] [PubMed]

4. Tegl, G.; Schiffer, D.; Sigl, E.; Heinzle, A.; Guebitz, G.M. Biomarkers for infection: Enzymes, microbes, and metabolites. Appl. Microbiol. Biotechnol. 2015, 99, 4595-4614. [CrossRef] [PubMed]

5. Schultz, G.; Wolcott, R.D. Wound infection and diagnostics in practice: What is emerging? Wounds Int. 2013, 4, 4-6.

6. Schiffer, D.; Blokhuis-Arkes, M.; van der Palen, J.; Sigl, E.; Heinzle, A.; Guebitz, G.M. Assessment of infection in chronic wounds based on the monitoring of elastase, lysozyme and myeloperoxidase activities. Br. J. Dermatol. 2015. [CrossRef] [PubMed]

7. Hajnsek, M.; Schiffer, D.; Harrich, D.; Koller, D.; Verient, V.; Palen, J.V.D.; Heinzle, A.; Binder, B.; Sigl, E.; Sinner, F; et al. An electrochemical sensor for fast detection of wound infection based on myeloperoxidase activity. Sens. Actuators B Chem. 2015, 209, 265-274. [CrossRef] 
8. Hasmann, A.; Wehrschuetz-Sigl, E.; Marold, A.; Wiesbauer, H.; Schoeftner, R.; Gewessler, U.; Kandelbauer, A.; Schiffer, D.; Schneider, K.P.; Binder, B.; et al. Analysis of myeloperoxidase activity in wound fluids as a marker of infection. Ann. Clin. Biochem. 2013, 50, 245-254. [CrossRef] [PubMed]

9. Johnston, K.J.; Ashford, A.E. A simultaneous-coupling azo dye method for the quantitative assay of esterase using alpha-naphthyl acetate as substrate. Histochem. J. 1980, 12, 221-234. [CrossRef] [PubMed]

10. Sampietro, D.A.; Vattuone, M.A.; Catalán, C.A.N. A new colorimetric method for determination of alkylresorcinols in ground and whole-cereal grains using the diazonium salt Fast Blue RR. Food Chem. 2009, 115, 1170-1174. [CrossRef]

11. McGoldrick, C.A.; Jiang, Y.L.; Paromov, V.; Brannon, M.; Krishnan, K.; Stone, W.L. Identification of oxidized protein hydrolase as a potential prodrug target in prostate cancer. BMC Cancer 2014, 14, 77. [CrossRef] [PubMed]

12. Franck, T.; Kohnen, S.; Boudjeltia, K.Z.; van Antwerpen, P.; Bosseloir, A.; Niesten, A.; Gach, O.; Nys, M.; Deby-Dupont, G.; Serteyn, D. A new easy method for specific measurement of active myeloperoxidase in human biological fluids and tissue extracts. Talanta 2009, 80, 723-729. [CrossRef] [PubMed]

13. Doerge, D.R.; Divi, R.L.; Churchwell, M.I. Identification of the colored guaiacol oxidation product produced by peroxidases. Anal. Biochem. 1997, 250, 10-17. [CrossRef] [PubMed]

(C) 2015 by the authors; licensee MDPI, Basel, Switzerland. This article is an open access article distributed under the terms and conditions of the Creative Commons by Attribution (CC-BY) license (http://creativecommons.org/licenses/by/4.0/). 